Protestantismo em Revista é licenciada sob uma Licença Creative Commons.

http://dx.doi.org/10.22351/nepp.v43i2.3052

\title{
A autoria de Hebreus: a sobrevida acadêmica da Hipótese Paulina
}

\author{
The authorship of Hebrews: the academic survival of the Pauline Hypothesis
}

Isaac Malheiros*

\begin{abstract}
Resumo
A autoria de Hebreus provocou um debate que começou nos primeiros anos da igreja cristã, diminuiu entre os séculos $\mathrm{V}$ e $\mathrm{XV}$, renasceu durante a Reforma do século XVI, e perdura até hoje. O objetivo central desse artigo é, através de uma pesquisa bibliográfica, demonstrar que a antiga sugestão de que Paulo é o autor de Hebreus não está completamente descartada, tendo recentemente ganhado renovada sobrevida na academia. Este artigo não fará uma análise pormenorizada dos argumentos favoráveis ou contrários à autoria paulina, mas uma exposição histórica dessa proposta, com ênfase em suas defesas mais recentes.
\end{abstract}

Palavras-chave

Epístola aos Hebreus. Autoria de Hebreus. Autenticidade de Hebreus.

\begin{abstract}
The authorship of Hebrews provoked a debate that began in the early years of Christianity, was diminished between the fifth and fifteenth centuries, was reborn during the Reformation of the sixteenth century, and lasts until today. The central aim of this article is, through a bibliographical research, to demonstrate that the old suggestion that Paul is the author of Hebrews is not completely discarded, having recently gained renewed survival in the academy. This article will not make a detailed analysis of favorable or contrary arguments to the Pauline authorship, but a historical exposition of this proposal, with emphasis on its most recent defenses.
\end{abstract}

\section{Keywords}

Epistle to the Hebrews. Authorship of Hebrews. Authenticity of Hebrews.

\section{Considerações iniciais}

O debate sobre a autoria de Hebreus foi estabelecido logo cedo na igreja cristã, diminuiu entre os séculos V e XV, renasceu durante a Reforma do século XVI, e perdura até hoje. O objetivo central desse artigo é demonstrar que nem mesmo a antiga sugestão de

[Texto recebido em julho de 2017 e aceito em janeiro de 2018, com base na avaliação cega por pares realizada por pareceristas ad hoc]

* Doutorando em Teologia (Faculdades EST). Mestre em Teologia (Faculdades EST). Professor do Seminário Adventista Latino-Americano de Teologia (IAP, Ivatuba-PR). E-mail: isaacmeira@gmail.com 
que Paulo é o autor de Hebreus está completamente descartada, tendo recentemente ganhado renovada sobrevida na academia. Neste artigo, o autor de Hebreus será identificado como "o Autor" ou "o autor de Hebreus". Não se trata aqui de uma análise pormenorizada dos argumentos favoráveis ou contrários à autoria paulina, mas uma exposição histórica dessa proposta, com ênfase em suas defesas mais recentes.

O misterioso autor de Hebreus é considerado um dos três grandes teólogos do Novo Testamento (juntamente com Paulo e o autor do quarto evangelho). ${ }^{1}$ Apesar das informações que Hebreus fornece sobre o Autor, $^{2}$ as tentativas de identificar as circunstâncias históricas específicas esbarram em um bom número de conjecturas e especulações, por isso, os pesquisadores geralmente são cautelosos diante de afirmações categóricas sobre a autoria. Exceto quando essa afirmação categórica é: Paulo não escreveu Hebreus. Esse consenso negativo a respeito da hipótese paulina é justificado? Este artigo também pretende discutir essa questão, especialmente à luz de pesquisas mais recentes.

\section{As especulações sobre a autoria de Hebreus}

Muitas propostas de identificação da autoria de Hebreus já foram feitas, e este artigo não dedicará espaço para avaliar cada uma delas. ${ }^{3}$ Dentre as propostas estão Apolo, ${ }^{4}$ Barnabé, ${ }^{5}$ Priscila, ${ }^{6}$ Lucas, ${ }^{7}$ Silas, ${ }^{8}$ Pedro, ${ }^{9}$ Ariston (o presbítero), ${ }^{10}$ Filipe, ${ }^{11}$ Judas, ${ }^{12}$

1 LINDARS, Barnabas. The theology of the Letter to the Hebrews. Cambridge: Cambridge University Press, 2003. p. 1, 25.

2 É evidente no próprio texto de Hebreus, por exemplo, que o Autor é um profundo conhecedor do Antigo Testamento, conhece com detalhes o histórico do seu grupo de ouvintes (Hb 10.32-34), incluindo a história de sua conversão ao cristianismo. O Autor cita seus encontros prévios com os ouvintes/leitores (Hb 13.19), conhece Timóteo e expressa seu desejo de visitar os destinatários novamente com Timóteo ( $\mathrm{Hb} 13.23)$.

3 Para uma apresentação e breve avaliação das principais propostas de autoria, ver AGUIAR, Adenilton T. et al. A autoria de Hebreus: uma breve incursão por vinte séculos de debate. Hermenêutica, Cachoeira, v. 11, n. 01, p. 113-130, 2011.

4 JOHNSON, Luke T. Hebrews: A Commentary. Louisville: Westminster John Knox Press, 2006. p. 43.

5 ALLEN, David L. Hebrews. The New American Commentary: an exegetical and theological exposition of Holy Scripture. v. 35. Nashville: Broadman \& Holman, 2010. p. 43-45.

6 HOPPIN, Ruth. The Epistle to the Hebrews is Priscilla's Letter. In: LEVINE, Amy-Jill (Ed.). A Feminist Companion to the Catholic Epistles and Hebrews. London: T\&T Clark, 2004. p. 147-170.

7 ALLEN, David L. Lukan Authorship of Hebrews. Nashville: Broadman \& Holman, 2010.

8 HEWITT, Thomas. The Epistle to the Hebrews. Grand Rapids: Eerdmans, 1960. p. 26-32.

9 WELCH, Adam. The authorship of the Epistle to the Hebrews. Edinburgh: Oliphant, Anderson \& Ferrier, 1898. p. 1-33.

10 CHAPMAN, John. Aristion, author of the Epistle to the Hebrews. Revue Benedictine, v. 22, n. 1-4, p. 50-64, 1905. Disponível em: <http://www.brepolsonline.net/doi/pdf/10.1484/J.RB.4.03094>. Acesso em: 27 abr. 2017.

11 RAMSAY, William. The Date and Authorship of the Epistle to the Hebrews. The Expositor, v. 9, p. 401-422, 1899. Disponível em: <https://biblicalstudies.org.uk/pdf/expositor/series5/09-401.pdf>. Acesso em: 14 mar. 2017.

12 DUBARLE, André-Marie. Rédacteur et destinataires de l'Épitre aux Hébreux. Revue Biblique, v. 48, n. 4, p. 506-529, 1939. Disponível em: <www.jstor.org/stable/44103098>. Acesso em: 23 abr. 2017. 
Epafras, ${ }^{13}$ Timóteo, ${ }^{14}$ e até Maria (mãe de Jesus). ${ }^{15}$ Geralmente, essas sugestões são de caráter altamente especulativo, e suas conclusões estão além dos limites fornecidos pelas evidências. Moffat afirma que tais hipóteses expressam apenas "um desejo irreprimível de construir romances do NT". 16

É possível detectar um padrão na abordagem retórica de pesquisas sobre esse tema. Os pesquisadores acumulam especulações substanciais em torno de algumas evidências, e então fazem uma afirmação mais ousada em cima da argumentação que foi construída. Mas quando avaliamos com mais cuidado, cada elemento da somatória argumentativa é muito especulativo.

Em geral, os propositores de tais hipóteses apresentam evidências de que seus candidatos pelo menos não deveriam ser excluídos do grupo de possíveis autores de Hebreus, mas mesmo assim concluem que Hebreus deve ser atribuído àquele candidato.

A questão da autoria paulina foi submetida até mesmo a análises estatísticas computacionais. Um grupo das Engenharias Biomédica, Elétrica e Eletrônica da Universidade de Adelaide na Austrália tentou usar uma variedade de métodos de análise computacional para detectar a autoria de escritos literários. Pelo menos três dessas pesquisas usaram Hebreus como um estudo de caso, com resultados muito divergentes: dois testes concluíram que Hebreus mostra uma grande semelhança com os escritos de Paulo, ${ }^{17}$ e um teste concluiu que é muito improvável que Paulo tenha escrito Hebreus (em vez disso, Hebreus mostraria maior semelhança com a Epístola de Barnabé). ${ }^{18}$

13 ANDERSON, Charles P. The Epistle to the Hebrews and the Pauline Letter Collection. Harvard Theological Review, v. 59, n. 4, p. 429-438, 1966. Disponível em: <www.jstor.org/stable/1509206>. Acesso em: 14 mar. 2017.

14 LEGG, John D. "Our brother Timothy": A Suggested Solution to the Problem of the Authorship of the Epistle to the Hebrews. The Evangelical Quarterly, v. 40, p. 220-223, 1968. Disponível em: <https://biblicalstudies.org.uk/pdf/eq/1968-4_220.pdf>. Acesso em: 14 mar. 2017.

15 Essa proposta foi feita em 1976 por Josephine Massyngberde Ford. Para uma visualização resumida das principais propostas e seus respectivos defensores, ver ALLEN, 2010, p. 13. Para uma análise geral das principais propostas, ver ELLINGWORTH, Paul. The Epistle to the Hebrews: A Commentary on the Greek Text. The New International Greek Testament Commentary. Grand Rapids: Eerdmans, 1993. p. 3-21.

16 MOFFATT, James. A critical and exegetical commentary on the Epistle to the Hebrews. The International Critical Commentary. Edinburgh: T. \& T. Clark, 1957. p. xx.

17 BERRYMAN, M. J.; ALLISON, A.; ABBOTT D. Statistical Techniques for Text Classification Based on Word Recurrence Intervals. Fluctuations and Noise Letters, v. 3, n. 1, 2003. p. 1-10. Disponível em: <http://www.eleceng.adelaide.edu.au/Personal/dabbott/publications/FNL_berryman2003.pdf>.

Acesso em: 28 abr. 2017; SABORDO, Madeleine; CHAI, Shong Y.; BERRYMAN, Matthew J.; ABBOT, Derek. Who wrote the letter to the Hebrews? - Data mining for detection of text authorship. Smart Structures, Devices, and System II, Proceedings of SPIE, v. 5649, 2005. p. 513-524. Disponível em: <http:/ / ro.uow.edu.au/cgi/viewcontent.cgi?article=7837\&context=engpapers>. Acesso em: 28 abr. 2017.

18 PUTNISA, Tālis J.; SIGNORIELLOA, Domenic J.; JAINA, Samant; BERRIMAN, Matthew J.; ABBOT, Derek. Advanced text authorship detection methods and their application to biblical texts. Complex Sistems, Proceedings of SPIE, v. 6039, 2006. p. 1-13. Disponível em: <http://ro.uow.edu.au/cgi/viewcontent.cgi?article=7832\&context=engpapers>. Acesso em: 28 abr. 2017. 
Há também a hipótese de que Hebreus seja um pseudepígrafo, escrito por um autor desconhecido, que propositalmente alegou autoria paulina para acrescentar Hebreus ao corpo conhecido de escritos paulinos. ${ }^{19}$

Talvez, a melhor opinião a respeito da autoria de Hebreus continue sendo a de Orígenes: só Deus sabe. ${ }^{20}$ Por isso, muitos comentaristas permanecem agnósticos a respeito desse tópico. Segundo Moffatt, "nosso orgulho moderno se ressente de ser desconcertado por um documento antigo, mas é melhor admitir que ainda não somos mais sábios sobre esse assunto do que Orígenes foi, dezessete séculos atrás". ${ }^{21}$

\section{A história da hipótese paulina}

Há considerável evidência de que o Autor tenha sido influenciado por Paulo ou pela teologia paulina. Talvez a maneira mais simples de explicar essa influência seja simplesmente admitir que Paulo é o autor do livro de Hebreus. Embora esta não seja uma visão popular hoje, as tradições mais antigas identificam Paulo como o autor, mas isso foi questionado desde a Reforma e agora é um ponto de vista raramente defendido.

Hebreus foi frequentemente associado às cartas paulinas. $\mathrm{O}$ texto existente mais antigo de Hebreus está no Papiro Chester Beatty II (P46), datado entre 175-225 d.C., que contém epístolas atribuídas a Paulo, começando com Romanos e incluindo Hebreus logo em seguida. 22 Muitos pais da igreja primitiva, especialmente os pais Alexandrinos, acreditavam que Paulo havia escrito Hebreus. Clemente de Alexandria (150-215) e Orígenes (185-253), por exemplo, acreditavam na autoria paulina. No final do segundo século, Orígenes pensou que o "peso da tradição" estava por trás da autoria paulina, mas no final disse que "só Deus sabe" quem escreveu o livro. Ele continua dizendo: "Esta escrita é inspirada, embora não saibamos quem a escreveu". ${ }^{23}$

Foi apenas a partir da Reforma do século XVI que esta crença tradicional foi fortemente questionada, especialmente por Calvino e Lutero. Nos séculos XVII, XVIII e XIX, houve intensa defesa da autoria paulina, mas o século XX registrou um crescente ceticismo em relação à teoria paulina e o surgimento de uma enxurrada de teorias sobre a autoria de Hebreus. Charles Forster escreveu aquela que é provavelmente a defesa mais

19 ROTSCHILD, Clare K. Hebrews as Pseudepigraphon. Tübingen: Mohr Siebeck, 2009.

20 KISTEMAKER, Simon J. Exposition of the Epistle to the Hebrews. Baker New Testament Commentary. Welwyn: Evangelical Press, 1984. p. 6.

21 MOFFAT, 1957, p. xx

22 O Papiro Chester Beatty II contém "86 folhas quase perfeitas de um códice das epístolas de Paulo que tinha, num único caderno, cerca de 104 folhas, das quais as últimas cinco eram provavelmente em branco. A ordem das epístolas é a seguinte: Romanos, Hebreus, 1 e 2 Coríntios, Efésios, Gálatas, Filipenses, Colossenses e 1 e 2 Tessalonicenses. Estão faltando as pastorais, que talvez nunca fizeram parte do códice. A importância desse ms., datado do final do século II ou início do III, é seu testemunho acerca das epístolas paulinas, incluindo-se Hebreus, pelo menos um século antes dos grandes unciais". PAROSCHI, Wilson. Crítica textual do Novo Testamento. São Paulo: Vida Nova, 2010. p. 45.

23 Citado por Eusébio de Cesareia em História Eclesiástica 6.25.11-13. 
detalhada da autoria paulina de Hebreus. Ele esperava resolver a questão da autoria de uma vez por todas através de um exame aprofundado da evidência interna. ${ }^{24}$

Embora a maioria dos estudiosos do século XX tenha rejeitado a autoria paulina de Hebreus, essa ideia foi defendida de forma competente pelo erudito católico William Leonard no Authorship of the Epistle to the Hebrews, ${ }^{25}$ que é uma das mais importantes apresentações da teoria da autoria paulina do século XX.

Allen destaca o fato impressionante de que praticamente nenhum comentarista de Hebreus se envolveu de fato com os argumentos de Leonard a favor da autoria paulina, ele foi aparentemente apenas ignorado. ${ }^{26}$ Leonard apresentou uma grande quantidade de evidências para sustentar sua opinião. $O$ trabalho de Leonard, juntamente com o de Moses Stuart ${ }^{27}$ e o de Forster no século XVIII, somam cerca de 800 páginas, e formam a mais abrangente compilação de evidências para a hipótese da autoria paulina.

Com o crescente consenso contra a autoria paulina no século $X X$, a academia se aproximava cada vez mais de uma unanimidade: a "Epístola de Paulo aos Hebreus" não era epístola, não era de Paulo, e nem foi escrita aos Hebreus. ${ }^{28}$ Essa suposta unanimidade ainda é afirmada. ${ }^{29}$ A situação parece ter se estabilizado, e a posição agnóstica aparentemente tornou-se majoritária entre os acadêmicos. Na avaliação de Attridge, a maioria dos estudiosos já deixou de se preocupar com a autoria paulina. ${ }^{30}$ Porém, a autoria de Hebreus continua sendo um campo de intensa discussão especializada. As sugestões se multiplicaram, e a crença de que o Autor foi o apóstolo Paulo perdeu força, mas jamais foi descartada totalmente. De fato, a crença na autoria paulina ganhou novo fôlego recentemente, com a publicação de David Black, como veremos neste artigo. ${ }^{31}$

\section{O alegado consenso negativo: Paulo não escreveu Hebreus}

Como os "limites do conhecimento histórico impedem a identificação positiva do escritor", 32 não existe um consenso sobre quem escreveu Hebreus, o consenso é totalmente negativo (Paulo não escreveu). Atualmente, é preciso coragem para um estudioso arriscar sua reputação desafiando uma conclusão tão bem assegurada na academia.

24 FORSTER, Charles. The Apostolical Authority of the Epistle to the Hebrews. London: James Duncan, 1836. Disponível em: <https://archive.org/details/apostolicalautho00fors>. Acesso em: 17 abr. 2017.

25 LEONARD, William. Authorship of the Epistle to the Hebrews. Rome: Vatican Polyglot, 1939.

26 ALLEN, 2010, p. 52.

27 STUART, Moses. A Commentary on the Epistle to the Hebrews. Andover: Warren F. Draper, 1876. p. 117-156.

28 VANHOYE, Albert. Structure and Message of the Epistle to the Hebrews. Roma: Editrice Pontificio Istituto Biblico, 1989. p. 5.

29 BORING, M. Eugene. An Introduction to the New Testament: History, Literature, Theology. Louisville: Westminster John Knox Press, 2012. p. 414 (414-421); HOUTMAN, Alberdina; POORTHUIS, Marcel; SCHWARTZ, Joshua J.; TURNER, Joseph (Eds.). The Actuality of Sacrifice: Past and Present. Leiden: Brill, 2014. p. 107-108.

30 GELARDINI, Gabriella (Ed.). Hebrews: Contemporay methods, new insights. Leiden: Brill, 2005. p. vii.

31 BLACK, David A. The authorship of Hebrews: the case for Paul. Gonzalez: Energion, 2013.

32 LANE, William. Hebrews 1-8. Word Bible Commentary. N. 47a. Dallas: Word Incorporated, 1991. p. xlix. 
Nos anos 1990, uma análise linguística detalhada foi feita por Spicq e concluiu que "é impossível, do ponto de vista linguístico, atribuir a Paulo a paternidade direta de Hebreus". 33 Percebe-se que a autoria paulina é rejeitada sem meias palavras, e é fácil encontrar declarações como essa: "como é geralmente reconhecido hoje, quem quer que escreveu Hebreus, certamente não foi Paulo". 34

Essa certeza é apoiada por diversos outros autores. ${ }^{35}$ Ellingworth afirmou que "a ideia da autoria Paulina de Hebreus agora está quase universalmente abandonada". ${ }^{36}$ Attridge afirmou, em 1989, que a última pessoa a defender a autoria paulina havia sido William Leonard, em 1939. 37

Desenvolveu-se um consenso de que Paulo não é o Autor, mesmo entre os estudiosos católicos que agora sugerem que Hebreus foi escrito por um dos alunos de Paulo. 38 Boa parte dos comentaristas afirma taxativamente que Hebreus não é obra paulina, é considerada uma obra de autor desconhecido, e chega a ser classificada por alguns estudiosos católicos como deuterocanônica. 39

Vários estudiosos até desafiam a integridade do estranho capítulo 13 de Hebreus (especialmente os versículos 22-25), que eles supõem terem sido anexados apenas para sugerir a autoria paulina aos leitores. ${ }^{40}$ Lindars afirma que a atribuição da carta a Paulo foi promovida para obter aceitação no cânon do Novo Testamento em um momento em que havia muita disputa sobre quais livros deveriam ser incluídos. ${ }^{41}$ Assim, Hebreus seria um caso intrigante de pseudepígrafo com a falsa autoria implícita, apenas sugerida.

No século XX, a predominância da interpretação filônica/platônica de Hebreus criou a tendência de ver pouca ou nenhuma conexão entre Hebreus e Paulo. McCullough

ELLINGWORTH, 1993, p. 12.

ATTRIDGE, Harold W. The Epistle to the Hebrews. Philadelphia: Fortress, 1989. p. 2.

ELLINGWORTH, 1993, p. 2.

ELLINGWORTH, 1993, p. 2.

ATTRIDGE, 1989, p. 2.

38 MCCULLOUGH, John C. Some Recent Developments in Research on the Epistle to the Hebrews. Irish Biblical Studies, v. 2, 1980, p. 141-165.

39 Deuterocanônicos do NT seriam os livros que foram discutidos, mas que acabaram entrando no Cânon do NT; ver HARDING, Mark. Disputed and Undisputed Letters of Paul. In: PORTER, Stanley E. The Pauline Canon. Atlanta: Society of Biblical Literature, 2009. p. 135; FITZMYER, J. A. Introdução às Epístolas do Novo Testamento. In: BROWN, R. E.; FITZMYER, J. A.; MURPHY, R. E. (Eds.). Novo Comentário Bíblico São Jerônimo do Novo Testamento e Artigos Sistemáticos. Santo André: Academia Cristã, 2011. p. 404; MANNUCCI, Valério. Bíblia, Palavra de Deus: Curso de introdução à Sagrada Escritura. São Paulo: Paulus, 2008. p. 223; METZGER, Bruce M. The Canon of the New Testament: Its Origen, Development, and Significance. Oxford: Clarendon Press, 2009. p. 239-247.

40 ATTRIDGE, 1989, p. 384-385; WEDDERBURN, Alexander J. M. The 'Letter' to the Hebrews and Its Thirteenth Chapter. New Testament Studies, v. 50, n. 3, p. 390-405, 2004. Disponível em: <https://www.cambridge.org/core/journals/new-testament-studies/article/the-letter-to-the-hebrewsand-its-thirteenth-chapter/1574CF4EFED15F9BA1F0F9337B36E5CD>. Acesso em: 16 abr. 2017.

41 LINDARS, 2003, p. 16. 
afirma que, de um modo geral, as especulações sobre a autoria paulina chegaram ao fim. ${ }^{42}$ Segundo McCullough, os esforços para identificar nomes falharam e os estudiosos estão começando a aceitar que o trabalho é anônimo (por exemplo, Attridge). ${ }^{43}$ Se, por um lado, os estudiosos modernos foram abandonando a noção de autoria paulina, por outro lado, eles reconheceram a inutilidade de se identificar o Autor com alguma pessoa específica historicamente reconhecida, e a opinião agnóstica foi paulatinamente assumindo a posição majoritária.

\section{O recente ressurgimento da hipótese paulina}

A ideia de que Hebreus é de autoria paulina sempre teve defensores, e recentemente, vários artigos e livros apareceram tentando reviver a hipótese paulina. Não faremos um levantamento bibliográfico exaustivo aqui, apenas apontaremos alguns exemplos importantes para demonstrar que a hipótese paulina ganhou sobrevida na academia.

Wiersbe defende a autoria paulina usando a amizade entre Timóteo e o apóstolo Paulo como uma evidência que confirma a autenticidade da homilia. ${ }^{44}$ Em Hebreus 13.23, percebe-se a afinidade entre o Autor e Timóteo: "notifico-vos que o irmão Timóteo foi posto em liberdade; com ele, caso venha logo, vos verei." Em Coríntios 4.17, Paulo declara abertamente que Timóteo é seu filho amado: "por esta causa, vos mandei Timóteo, que é meu filho amado e fiel no Senhor, o qual vos lembrará os meus caminhos em Cristo Jesus, como, por toda parte, ensino em cada igreja". Outro argumento usado por Wiersbe é a possível correspondência entre Gl 3.11 e Hb 10.38, através da sentença “o justo viverá pela fé".

Christos Sp. Voulgaris argumentou em 1999 a favor da autoria paulina, identificando conexões entre $\mathrm{Hb}$ 13.23, Fp 2.19-24 e Fm 22. ${ }^{45}$ Ele sugere que Hebreus foi escrito para os cristãos de Jerusalém após a morte de Tiago, com o objetivo de animá-los diante de uma perseguição renovada. Hebreus teria sido escrito alguns anos antes do início da Guerra Judaica no ano 66 d.C.

Voulgaris acredita, baseado em $\mathrm{Hb}$ 13.23, que Paulo enviou Timóteo numa missão anônima, sem mencionar sua intenção nem seu destino por questões de segurança. Quando Paulo escreveu aos Filipenses, ele também expressou o desejo de enviar Timóteo

42 MCCULLOUGH, John C. Hebrews in Recent Scholarship. Irish Biblical Studies, v. 16, 1994, p. 66-86, 108120.

43 MCCULLOUGH, 1994, p. 68.

44 WIERSBE, Warren W. Wiersbe's Expository Outlines on the New Testament. Wheaton: Victor Books, 1997. p. 674.

45 VOULGARIS, Christos Sp. Hebrews: Paul's Fifth Epistle from Prison. Greek Orthodox Theological Review, v. 44 n. $1-4, \quad$ p. $199-206, \quad 1999 . \quad$ Disponível em: <http:/ / connection.ebscohost.com/c/articles/6156722/hebrews-pauls-fifth-epistle-from-prison>. Acesso em: 22 fev. 2017. 
(Fp 2.19-24). E, como faz em $\mathrm{Hb}$ 13.23, Paulo também disse que planejava visitar os Filipenses (Fp 2.24). ${ }^{46}$ Para Voulgaris, todas as cartas que Paulo escreveu da prisão, inclusive Hebreus, foram escritas em Roma durante sua prisão domiciliar em 60-62 d.C. ${ }^{47}$ Paulo então escreve Hebreus para a igreja em Jerusalém para fortalecê-los na fé e melhorar sua relação com esses cristãos zelosos da lei.

Assim, Paulo estaria informando que Timóteo estava em missão (em Filipos), e tão logo ele retornasse, ambos iriam a Jerusalém visitar a igreja. ${ }^{48}$ A razão para Paulo não mencionar mais explicitamente sua prisão em Hebreus da forma como ele o faz em outras cartas seria a proximidade de sua libertação (ele esperava ser liberto antes que sua epístola chegasse ao destino), o que não ocorreu por causa da morte de Festo, governador da Judeia, e da agitação política e social que se seguiu. ${ }^{49}$ A ideia de Voulgaris é plausível, mas bastante especulativa.

Eta Linnemann publicou um artigo de três partes no ano $2000^{50}$ (publicado em inglês em 2002) $)^{51}$ demonstrando que os comentaristas muitas vezes exageraram na argumentação contra a autoria paulina. Ela avalia as evidências manuscritas, o testemunho da igreja primitiva, o estilo, o vocabulário, as particularidades de Hebreus usadas contra Paulo, e a linha de argumentação em Hebreus.

Linnemann demonstra similaridades léxicas, estilísticas e literárias entre Hebreus e as cartas paulinas, revivendo os argumentos de Forster, Moses Stuart e William Leonard. Ela afirma que Hebreus é tão bem documentado em manuscritos antigos quanto Romanos, e questiona como seria possível um livro anônimo ter sido incluído nos primeiros cânones, sugerindo implicitamente que a aceitação de Hebreus no cânon só pode ser explicada pelo reconhecimento primitivo de Paulo como o autor. ${ }^{52}$

Ela também aponta a evidência patrística para a autoria paulina, e alerta que o anonimato de Hebreus torna necessário exercer cada vez mais atenção em consideração de todos os fatos disponíveis. 53 Sobre o estilo de Hebreus, Linnemann critica aqueles que apontam para um suposto estilo inferior de Paulo, quase que difamando o apóstolo, como se ele fosse um ignorante incapaz de escrever em estilos diferentes. ${ }^{54}$ Allen (que não defende a autoria paulina) concorda com Linnemann nesse ponto, dizendo que o argumento estilístico tem sido utilizado de maneira exagerada por autores modernos que

46 VOULGARIS, 1999, p. 200-203.

47 VOULAGRIS, 1999, p. 204.

48 VOULGARIS, 1999, p. 205.

49 VOULGARIS, 1999, p. 205-206.

50 LINNEMANN, Eta. Wiederaufnahme-Prozess in Sachen des Hebräerbriefes. Fundamentum, 2, 2000, p. 102-112 (parte 1), p. 52-65 (parte 2), p. 88-110 (parte 3).

51 LINNEMANN, Eta. A Call for a Retrial in the Case of the Epistle to the Hebrews. Faith and Mission, v. 19, n. 2, 2002, p. 19-59.

52 LINNEMANN, 2002, p. 20.

53 LINNEMANN, 2002, p. 26.

54 LINNEMANN, 2002, p. 27. 
pretendem demonstrar a impossibilidade da autoria paulina, em vez de sua improbabilidade. ${ }^{55}$

Linnemann examina todos os exemplos dados por Attridge do suposto "grego melhor" utilizado em Hebreus ${ }^{56}$ (um argumento frequentemente usado contra a hipótese paulina) e encontra exemplos similares nas cartas paulinas, especialmente em Romanos. ${ }^{57}$ Ela encontra um correspondente paulino para cada uma das figuras de linguagem utilizadas em Hebreus, e conclui que, apesar de Hebreus apresentar um vocabulário mais amplo, todas as características do alegado grego superior de Hebreus são encontradas nos escritos paulinos. Em suma, Linnemann quer demonstrar que Hebreus e os escritos paulinos têm mais em comum do que a maioria dos comentaristas admite.

Sobre o anonimato, outra característica apontada contra a autoria paulina (já que Paulo costumeiramente se apresenta em suas cartas), Linneman argumenta que isso não é uma questão de estilo, mas de necessidade. Para ela, quem escreve anonimamente tem motivos para fazê-lo, e Paulo poderia ter usado o anonimato por causa do preconceito que os judeus tinham contra ele. ${ }^{58}$ Além disso, ela afirma que os outros candidatos geralmente apontados à autoria de Hebreus (Barnabé, Apolo, Lucas, Clemente de Roma) não teriam motivos para escrever anonimamente, e assim o anonimato seria um argumento a favor da autoria paulina. Essa justificativa para o anonimato já era utilizada no clássico comentário de Matthew Henry: “sendo o apóstolo aos gentios, que eram odiosos aos judeus, [Paulo] poderia ter imaginado adequado omitir o seu nome, para que o preconceito deles contra ele não os impedisse de ler e avaliar a epístola como o deveriam fazer". 59

Em outras palavras, Paulo seria o candidato ideal para ter escrito um livro com autoridade mesmo sem indicar sua autoria explicitamente no texto. Nichol explica de forma resumida esse argumento:

Concorda-se de maneira geral, que Hebreus foi escrita antes da queda de Jerusalém. Ora, o número de líderes na igreja era muito pequeno nos anos anteriores a $70 \mathrm{AD}$. Qual desses líderes poderia ter expressado um argumento tão profundo como o apresentado pelo livro de Hebreus? Sem termos de comparação, a pessoa mais provável é Paulo. Dizer que o autor foi um cristão desconhecido daquele período primitivo simplesmente propõe um novo problema. Como foi que um cristão que possuía a compreensão teológica e as faculdades lógicas necessárias para produzir

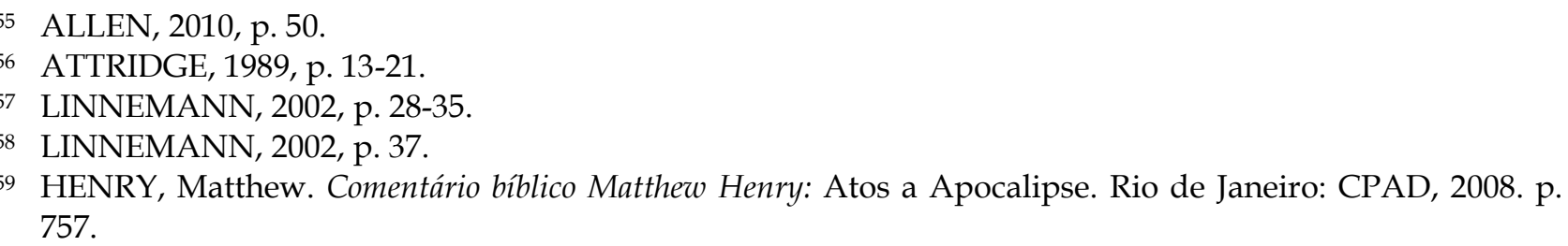


uma obra como Hebreus seria anônimo num tempo quando os líderes cristãos eram tão poucos e o registro dos militantes cristãos tão amplo? ${ }^{60}$

O melhor argumento recente em favor da autoria paulina é o de David Alan Black, que trouxe a autoria paulina de Hebreus de volta ao cenário acadêmico em uma série de artigos, posteriormente publicados em um livro, The Authorship of Hebrews: The Case For Paul. ${ }^{61}$ Ele publicou sua argumentação em três artigos em 1999 e $2001 .{ }^{62}$ Black aponta para os pais da igreja, que por muito tempo consideraram provável a autoria paulina. Sugere, baseado em Orígenes, que Lucas serviu como amanuense de Paulo, concluindo que Orígenes estava afirmando a autoria paulina.

Black também reapresenta as evidências linguísticas e teológicas de William Leonard, e acrescenta argumentos linguísticos e teológicos ainda mais abrangentes a favor da autoria paulina. Neste ponto, os três principais argumentos para a autoria são: 1) o uso de vocabulário similar (há muitas palavras e frases que aparecem apenas em Paulo e Hebreus no Novo Testamento), 63 2) semelhanças teológicas, e 3) o testemunho histórico dos pais da igreja. 64

A proposta de Black representou um ousado desafio a um consenso acadêmico. Ele afirma que "a evidência externa continua a ser negligenciada em certos círculos, e é a evidência externa que, na minha opinião, é probatória". 65

Apesar de não defenderem a autoria paulina, Georgi ${ }^{66}$ e Miller ${ }^{67}$ reconhecem as afinidades entre Hebreus e o cristianismo paulino, o que suscitou novas análises teológicas e literárias que contribuem para o atual debate acerca do significado teológico de Hebreus. Hurst também demonstra as afinidades entre Hebreus e Paulo, mesmo sem defender a autoria paulina. 68

60 NICHOL, Francis D. (Ed.). The Seventh-day Adventist Bible Commentary. v. 7. Hagerstown: Review and Herald, 2002. p. 378.

61 BLACK, 2013.

62 BLACK, David A. On the Pauline Authorship of Hebrews (Part 1): Overlooked Affinities between Hebrews and Paul. Faith and Mission, v. 16, n. 2, p. 32-51, 1999; BLACK, David A. On the Pauline Authorship of Hebrews (Part 2): The External Evidence Reconsidered. Faith and Mission, v. 16, n. 3, p. 7886, 1999; BLACK, David A. Who Wrote Hebrews? The Internal and External Evidence Reexamined. Faith and Mission, v. 18, n. 2, p. 3-26, 2001.

63 Alguns dos paralelos também poderiam ser explicados com o uso de uma fonte comum, mas isso seria ainda mais especulativo, visto que não temos essa fonte.

64 BLACK, 2001, p. 3-26.

65 BLACK, David A. On the authorship of Hebrews, entrevista, 8 out. 2011. Disponível em: <https://jesusparadigm.com/2011/10/08/on-the-authorship-of-hebrews/>. Acesso em: 22 abr. 2017.

66 GEORGI, Dieter. Hebrews and the Heritage of Paul. In: GELARDINI, Gabriella (Ed.). Hebrews: Contemporay methods, new insights. Leiden: Brill, 2005. p. 239-244.

67 MILLER, James C. Paul and Hebrews: A Comparison of Narrative Worlds. In: GELARDINI, Gabriella (Ed.). Hebrews: Contemporay methods, new insights. Leiden: Brill, 2005. p. 245-264.

68 HURST, Lincoln D. The Epistle to the Hebrews: Its background of thought. Cambridge: Cambridge University Press, 1990. p. 107-124. 
Jennifer L. Koosed e Robert P. Seesengood usaram uma combinação de abordagens mais recentes, como a crítica reader-response, a história da recepção de textos, a intertextualidade e a crítica cultural à questão da autoria para Hebreus. ${ }^{69}$ Koosed e Seesengood demonstram como, embora o texto seja anônimo, Hebreus foi "salvo" por causa da autoria paulina imputada sobre ele. Posteriormente, a análise filológica do texto estabeleceu a vasta aceitação do anonimato dele. Koosed e Seesengood concluem que esse movimento pode ter tido um viés: na era moderna/pós-moderna o estabelecimento do anonimato de Hebreus pode ter correspondido às necessidades do meio acadêmico, já que o apagamento do autor e da tradição garantiu o apagamento da autoridade de tal livro.70

Também na contramão do alegado consenso acadêmico a respeito da não-autoria paulina de Hebreus, Schenk afirma que a discussão acadêmica não conseguiu chegar a um consenso definitivo, e que é melhor evitar conclusões na questão da autoria. ${ }^{71}$

E o final do livro de Hebreus também continua sendo um tópico utilizado em defesa da autoria paulina. Michaels diz que não há evidência suficiente para excluir a possibilidade da autoria paulina, e, à luz do final de Hebreus, Paulo pode ser o "autor implícito". ${ }^{72}$ Por isso, Michaels acredita que seria mais apropriado descrever Hebreus como “deutero-paulino", e propõe que o próprio Timóteo seja o escritor do livro. ${ }^{73}$

Outra maneira de atribuir o livro de Hebreus a Paulo é o ressurgimento recente da antiga sugestão de que Lucas usou um sermão de Paulo para escrever Hebreus. ${ }^{74}$ Nessa hipótese, Lucas seria o editor responsável por fazer uma transcrição de uma apresentação oral de Paulo. As evidências seriam a antiga prática greco-romana da estenografia (ou taquigrafia) e publicação de discursos, e a presença da teologia paulina em Hebreus. Essa hipótese evita a objeção de que Hebreus não é linguisticamente paulino, apesar de por vezes refletir a teologia paulina. No mínimo, os defensores dessa hipótese propõem que é possivel que Paulo seja a fonte e Lucas o editor de Hebreus, uma hipótese admitida como possível até mesmo por David Black. ${ }^{75}$ Com base na evidência das cartas de Paulo, e nos livros de Lucas e Atos, Pitts e Walker, por exemplo, propõem que Lucas, o companheiro

69 KOOSED, Jennifer L.; SEESENGOOD, Robert P. Constructions and Collusions: The Making and Unmaking of Identity in Qoheleth and Hebrews. In: GELARDINI, Gabriella (Ed.). Hebrews: Contemporay methods, new insights. Leiden: Brill, 2005. p. 265-280.

70 KOOSED; SEESENGOOD, 2005, p. 265-280.

71 SCHENCK, Kenneth L. Cosmology and Eschatology in Hebrews: The Settings of the Sacrifice. Cambridge: Cambridge University Press, 2007. p. 2.

72 MICHAELS, J. Ramsay. Hebrews. In: COMFORT, Philip W. (Ed.). Cornerstone Biblical Commentary. v. 17. Carol Stream: Tyndale House Publishers, 2009. p. 305-454.

73 MICHAELS, 2009, p. 310-311.

74 Esta foi a sugestão de PITTS, Andrew; WALKER, Joshua. The Authorship of Hebrews: A Further Development in the Luke-Paul Relationship. In: PORTER, Stanley E.; LAND, Christopher D. Paul and His Social Relations. Leiden: Brill, 2012. p. 143-184.

75 BLACK, 2001, p. 23, nota 3. 
de viagem de Paulo, transcreveu um discurso paulino apresentado em uma sinagoga da Diáspora, e posteriormente editou o discurso e o publicou como um texto literário. ${ }^{76}$

Em outras palavras, em vez de perguntar "Quem escreveu Hebreus?", os pesquisadores de Hebreus deveriam fazer duas perguntas: "Quem pregou Hebreus?" e "Quem editou e publicou Hebreus?". A antiga hipótese de que Paulo teria escrito Hebreus em hebraico e Lucas teria traduzido para o grego também continua sendo considerada. ${ }^{77}$

Tais tentativas são dignas de consideração, uma vez que levam a sério a inegável influência paulina no livro de Hebreus e tentam trabalhar com evidências materiais. No entanto, a sugestão de que Hebreus é a transcrição de um sermão apenas move a questão da autoria um passo atrás, para: "quem foi o orador original deste sermão transcrito?".

David Allen é hoje um dos principais defensores da proposta de autoria lucana de Hebreus. ${ }^{78}$ No entanto, embora a maioria dos estudiosos hoje desconsidere Paulo como autor de Hebreus, Allen acredita que essa possibilidade não deve ser tão facilmente descartada. ${ }^{79}$ Paulo era amplamente considerado como o autor de Hebreus entre os primeiros pais da igreja, e os atuais defensores da autoria paulina também identificaram muitas afinidades literárias e teológicas entre os escritos paulinos e Hebreus.

Allen examina em detalhes consideráveis os argumentos de William Leonard, Eta Linnemann e David Alan Black para a autoria direta de Paulo, e conclui que, embora a evidência acumulada a favor da autoria paulina seja considerável e impressionante, $o$ estilo literário e as ênfases teológicas ainda são significativamente diferentes, tornando a autoria paulina improvável (mas não impossível). Outras evidências que afastam a autoria paulina incluem divergências na argumentação e na prática de citação do Antigo Testamento, a ausência de uma identificação (como Paulo faz em todas as suas outras cartas), e o fato do Autor se colocar entre uma geração posterior de crentes ( $\mathrm{Hb} 2.3)$. No entanto, Allen admite que há afinidades entre Hebreus e as cartas paulinas, e que essas afinidades sugerem que o Autor era um associado de Paulo e era influenciado pela teologia de Paulo (para Allen, Lucas é um dos principais candidatos). ${ }^{80}$

\section{Considerações finais}

Para qualquer pesquisador aberto à evidência, torna-se claro que a hipótese paulina não pode ser deixada de lado com tanta facilidade, como costuma ocorrer nas

76 PITTS; WALKER, 2012, p. 183-184.

77 WALVOORD, John F.; ZUCK, Roy B. (Eds.). The Bible Knowledge Commentary: an exposition of the Scriptures. v. 2. Wheaton: Victor Books, 1983-1985. p. 777-778.

78 ALLEN, 2010.

79 ALLEN, 2010, p. 45.

80 ALLEN, 2010, p. 46-77. 
obras contemporâneas. Como observou Allen, o nome de Paulo ainda deve permanecer no alto escalão dos possíveis candidatos à autoria de Hebreus. ${ }^{81}$

Todas as hipóteses possíveis apresentam problemas, e qualquer impressão de que há algum consenso acadêmico nesse tema é frágil. Geralmente, as sugestões de consenso são de caráter altamente especulativo, conclusões que estão além dos limites de sua evidência.

A impressão é que preferimos qualquer solução que não seja excessivamente improvável a simplesmente admitir que não temos essa alegada certeza de que não foi Paulo. A posição agnóstica nesse assunto parece aceitável, não há nenhum erro em admitir que nós realmente não sabemos quem foi. Mas a proposta da autoria paulina certamente merece permanecer na mesa junto com as demais propostas.

Um dos principais argumentos contra a autoria paulina é que Hebreus é tão diferente dos outros escritos de Paulo, tanto em estilo quanto em conteúdo, que só pode ter sido escrito por outra pessoa. Mas é curioso como alguns estudiosos que não acreditam na existência de dois ou três Isaías, ou na Hipótese Documental (Teoria das Fontes) para o Pentateuco com base em diferenças de estilo e conteúdo, estão convencidos de que Paulo não poderia ter escrito Hebreus.

Em suma, há pesquisadores que justificam uma mesma autoria para textos de estilos e conteúdos diferentes, mas, ao mesmo tempo, não concedem esse benefício à ideia de que Paulo seja o autor de Hebreus. Como seria uma homilia paulina dirigida aos cristãos judeus? Não seriam esperadas algumas diferenças com relação às cartas direcionadas aos gentios? E é razoável supor que alguém precisa manter um estilo de escrita único?

Uma situação especial ou um grupo específico de pessoas poderia levar um autor a usar uma abordagem diferente daquela que ele geralmente usa. ${ }^{82} \mathrm{Na}$ opinião de Allen, um autor pode mudar seu estilo deliberadamente para acomodar seu assunto. Além disso, durante o período da vida de um autor, seu estilo pode alterar-se em termos de padrões de pensamento e conteúdo, e também em termos de estilo. Portanto, seria um exagero sugerir com base em comparações estilísticas que Paulo não poderia ter escrito Hebreus. ${ }^{83}$

Outro ponto é: a hipótese paulina tem material comparativo, o que não acontece com outras propostas. E isso leva a academia a conceder um tratamento desigual à autoria paulina, sendo exageradamente rigorosa com a autoria paulina e, por vezes,

81 ALLEN, David L. Hebrews. 2017, material não publicado. Disponível em: <http://bmats.edu/syllabi/ARCHIVE/PARSONS/AllenHebNAC\%20introd.pdf>. Acesso em: 12 mar. 2017.

82 MUELLER, Ekkehardt. Come boldly to the throne: sanctuary themes in Hebrews. Nampa: Pacific Press, 2003. p. 8.

83 ALLEN, 2010, p. 70. 
condescendente com as outras propostas. A rejeição de Paulo como autor por causa do estilo literário só tem força porque temos a autoria das cartas paulinas e porque temos o livro de Hebreus para comparar os estilos. Hebreus nos dá material comparativo suficiente para mostrar que, no mínimo, esta carta é diferente das epístolas que Paulo escreveu.

A dificuldade com as outras hipóteses reside no fato de que há pouca informação disponível para que elas pareçam mais seguras. Se Paulo, ou Paulo com Lucas, forem hipóteses excluídas, simplesmente não resta muito material relevante para produzir uma comparação, como exigem as evidências internas.

No caso de Priscila, por exemplo, não temos nada que ela escreveu, nem informações sobre sua teologia. Tudo o que sabemos é que ela se associou a Paulo. Então, neste caso de Priscila, simplesmente não temos como avaliar as evidências internas, os critérios estilísticos e teológicos.

No mínimo, a proposta da autoria paulina, embora não apresente evidências conclusivas, deveria ter novamente espaço respeitável entre as demais propostas, e não ser descartada com tanta facilidade ou ser reduzida a simples comentários em notas de rodapé.

\section{Referências}

AGUIAR, Adenilton T. et al. A autoria de Hebreus: uma breve incursão por vinte séculos de debate. Hermenêutica, Cachoeira, v. 11, n. 01, p. 113-130, 2011.

ALLEN, David L. Hebrews. 2017, material não publicado. Disponível em: <http://bmats.edu/syllabi/ARCHIVE/PARSONS/AllenHebNAC\%20introd.pdf>. Acesso em: 12 mar. 2017.

. The New American Commentary: an exegetical and theological exposition of Holy Scripture. v. 35. Nashville: Broadman \& Holman, 2010. . Lukan Authorship of Hebrews. Nashville: Broadman \& Holman, 2010.

ANDERSON, Charles P. The Epistle to the Hebrews and the Pauline Letter Collection. Harvard Theological Review, v. 59, n. 4, p. 429-438, 1966. Disponível em:

<www.jstor.org/stable/1509206>. Acesso em: 14 mar. 2017.

ATTRIDGE, Harold W. The Epistle to the Hebrews. Philadelphia: Fortress, 1989.

BERRYMAN, M. J.; ALLISON, A.; ABBOTT D. Statistical Techniques for Text Classification Based on Word Recurrence Intervals. Fluctuations and Noise Letters, v. 3, n. 1, 2003. Disponível em:

<http://www.eleceng.adelaide.edu.au/Personal/dabbott/publications/FNL_berryman2 003.pdf>. Acesso em: 28 abr. 2017. 
BLACK, David A. On the authorship of Hebrews, entrevista, 8 out. 2011. Disponível em: <https://jesusparadigm.com/2011/10/08/on-the-authorship-of-hebrews/>. Acesso em: 22 abr. 2017.

. On the Pauline Authorship of Hebrews (Part 1): Overlooked Affinities between Hebrews and Paul. Faith and Mission, v. 16, n. 2, p. 32-51, 1999.

. On the Pauline Authorship of Hebrews (Part 2): The External Evidence Reconsidered. Faith and Mission, v. 16, n. 3, p. 78-86, 1999.

. The authorship of Hebrews: the case for Paul. Gonzalez: Energion, 2013.

. Who Wrote Hebrews? The Internal and External Evidence Reexamined. Faith and Mission, v. 18, n. 2, p. 3-26, 2001.

BORING, M. Eugene. An Introduction to the New Testament: History, Literature, Theology. Louisville: Westminster John Knox Press, 2012.

CHAPMAN, John. Aristion, author of the Epistle to the Hebrews. Revue Benedictine, v. 22, n. 1-4, p. 50-64, 1905. Disponível em:

<http:/ / www.brepolsonline.net/doi/pdf/10.1484/J.RB.4.03094>. Acesso em: 27 abr. 2017.

DUBARLE, André-Marie. Rédacteur et destinataires de l'Épitre aux Hébreux. Revue Biblique, v. 48, n. 4, p. 506-529, 1939. Disponível em: <www.jstor.org/stable/44103098>. Acesso em: 23 abr. 2017.

ELLINGWORTH, Paul. The Epistle to the Hebrews: A Commentary on the Greek Text. The New International Greek Testament Commentary. Grand Rapids: Eerdmans, 1993.

FITZMYER, J. A. Introdução às Epístolas do Novo Testamento. In: BROWN, R. E.; FITZMYER, J. A.; MURPHY, R. E. (Eds.). Novo Comentário Bíblico São Jerônimo do Novo Testamento e Artigos Sistemáticos. Santo André: Academia Cristã, 2011.

FORSTER, Charles. The Apostolical Authority of the Epistle to the Hebrews. London: James Duncan, 1836. Disponível em: <https://archive.org/details/apostolicalautho00fors>. Acesso em: 17 abr. 2017.

GELARDINI, Gabriella (Ed.). Hebrews: Contemporay methods, new insights. Leiden: Brill, 2005.

GEORGI, Dieter. Hebrews and the Heritage of Paul. In: GELARDINI, Gabriella (Ed.). Hebrews: Contemporay methods, new insights. Leiden: Brill, 2005.

HARDING, Mark. Disputed and Undisputed Letters of Paul. In: PORTER, Stanley E. The Pauline Canon. Atlanta: Society of Biblical Literature, 2009.

HENRY, Matthew. Comentário bíblico Matthew Henry: Atos a Apocalipse. Rio de Janeiro: CPAD, 2008. 
HEWITT, Thomas. The Epistle to the Hebrews. Grand Rapids: Eerdmans, 1960.

HOPPIN, Ruth. The Epistle to the Hebrews is Priscilla's Letter. In: LEVINE, Amy-Jill (Ed.). A Feminist Companion to the Catholic Epistles and Hebrews. London: T\&T Clark, 2004.

HOUTMAN, Alberdina; POORTHUIS, Marcel; SCHWARTZ, Joshua J.; TURNER, Joseph (Eds.). The Actuality of Sacrifice: Past and Present. Leiden: Brill, 2014.

HURST, Lincoln D. The Epistle to the Hebrews: Its background of thought. Cambridge: Cambridge University Press, 1990.

JOHNSON, Luke T. Hebrews: A Commentary. Louisville: Westminster John Knox Press, 2006.

KISTEMAKER, Simon J. Exposition of the Epistle to the Hebrews. Baker New Testament Commentary. Welwyn: Evangelical Press, 1984.

KOOSED, Jennifer L.; SEESENGOOD, Robert P. Constructions and Collusions: The Making and Unmaking of Identity in Qoheleth and Hebrews. In: GELARDINI, Gabriella (Ed.). Hebrews: Contemporay methods, new insights. Leiden: Brill, 2005.

LANE, William. Hebrews 1-8. Word Bible Commentary. N. 47a. Dallas: Word Incorporated, 1991.

LEGG, John D. "Our brother Timothy": A Suggested Solution to the Problem of the Authorship of the Epistle to the Hebrews. The Evangelical Quarterly, v. 40, p. 220-223, 1968. Disponível em: <https://biblicalstudies.org.uk/pdf/eq/1968-4_220.pdf>. Acesso em: 14 mar. 2017.

LEONARD, William. Authorship of the Epistle to the Hebrews. Rome: Vatican Polyglot, 1939.

LINDARS, Barnabas. The theology of the Letter to the Hebrews. Cambridge: Cambridge University Press, 2003.

LINNEMANN, Eta. A Call for a Retrial in the Case of the Epistle to the Hebrews. Faith and Mission, v. 19, n. 2, 2002.

. Wiederaufnahme-Prozess in Sachen des Hebräerbriefes. Fundamentum, 2, 2000.

MANNUCCI, Valério. Bíblia, Palavra de Deus: Curso de introdução à Sagrada Escritura. São Paulo: Paulus, 2008.

MCCULLOUGH, John C. Hebrews in Recent Scholarship. Irish Biblical Studies, v. 16, 1994.

. Some Recent Developments in Research on the Epistle to the Hebrews. Irish Biblical Studies, v. 2, 1980.

METZGER, Bruce M. The Canon of the New Testament: Its Origen, Development, and Significance. Oxford: Clarendon Press, 2009. 
MICHAELS, J. Ramsay. Hebrews. In: COMFORT, Philip W. (Ed.). Cornerstone Biblical Commentary. v. 17. Carol Stream: Tyndale House Publishers, 2009.

MILLER, James C. Paul and Hebrews: A Comparison of Narrative Worlds. In: GELARDINI, Gabriella (Ed.). Hebrews: Contemporay methods, new insights. Leiden: Brill, 2005.

MOFFATT, James. A critical and exegetical commentary on the Epistle to the Hebrews. The International Critical Commentary. Edinburgh: T. \& T. Clark, 1957.

MUELLER, Ekkehardt. Come boldly to the throne: sanctuary themes in Hebrews. Nampa: Pacific Press, 2003.

NICHOL, Francis D. (Ed.). The Seventh-day Adventist Bible Commentary. v. 7. Hagerstown: Review and Herald, 2002.

PAROSCHI, Wilson. Crítica textual do Novo Testamento. São Paulo: Vida Nova, 2010.

PITTS, Andrew; WALKER, Joshua. The Authorship of Hebrews: A Further Development in the Luke-Paul Relationship. In: PORTER, Stanley E.; LAND, Christopher D. Paul and His Social Relations. Leiden: Brill, 2012.

PUTNISA, Tālis J.; SIGNORIELLOA, Domenic J.; JAINA, Samant; BERRIMAN, Matthew J.; ABBOT, Derek. Advanced text authorship detection methods and their application to biblical texts. Complex Sistems, Proceedings of SPIE, v. 6039, 2006, p. 1-13. Disponível em: <http:/ / ro.uow.edu.au/cgi/ viewcontent.cgi?article=7832\&context=engpapers $>$. Acesso em: 28 abr. 2017.

RAMSAY, William. The Date and Authorship of the Epistle to the Hebrews. The Expositor, v. 9, p. 401-422, 1899. Disponível em:

<https:/ / biblicalstudies.org.uk/pdf/expositor/series5/09-401.pdf>. Acesso em: 14 mar. 2017.

ROTSCHILD, Clare K. Hebrews as Pseudepigraphon. Tübingen: Mohr Siebeck, 2009.

SABORDO, Madeleine; CHAI, Shong Y.; BERRYMAN, Matthew J.; ABBOT, Derek. Who wrote the letter to the Hebrews? - Data mining for detection of text authorship. Smart Structures, Devices, and System II, Proceedings of SPIE, v. 5649, 2005. Disponível em: <http:/ / ro.uow.edu.au/cgi/ viewcontent.cgi?article=7837\&context=engpapers $>$. Acesso em: 28 abr. 2017.

SCHENCK, Kenneth L. Cosmology and Eschatology in Hebrews: The Settings of the Sacrifice. Cambridge: Cambridge University Press, 2007.

STUART, Moses. A Commentary on the Epistle to the Hebrews. Andover: Warren F. Draper, 1876. 
VANHOYE, Albert. Structure and Message of the Epistle to the Hebrews. Roma: Editrice Pontificio Istituto Biblico, 1989.

VOULGARIS, Christos Sp. Hebrews: Paul's Fifth Epistle from Prison. Greek Orthodox Theological Review, v. 44 n. 1-4, p. 199-206, 1999. Disponível em:

$<$ http://connection.ebscohost.com/c/articles/6156722/hebrews-pauls-fifth-epistle-fromprison>. Acesso em: 22 fev. 2017.

WALVOORD, John F.; ZUCK, Roy B. (Eds.). The Bible Knowledge Commentary: an exposition of the Scriptures. v. 2. Wheaton: Victor Books, 1983-1985.

WEDDERBURN, Alexander J. M. The 'Letter' to the Hebrews and Its Thirteenth Chapter. New Testament Studies, v. 50, n. 3, p. 390-405, 2004. Disponível em:

<https://www.cambridge.org/core/journals/new-testament-studies/article/the-letterto-the-hebrews-and-its-thirteenth-chapter/1574CF4EFED15F9BA1F0F9337B36E5CD>. Acesso em: 16 abr. 2017.

WELCH, Adam. The authorship of the Epistle to the Hebrews. Edinburgh: Oliphant, Anderson \& Ferrier, 1898.

WIERSBE, Warren W. Wiersbe's Expository Outlines on the New Testament. Wheaton: Victor Books, 1997. 